\title{
Overexpression of Annexin A1 Is an Independent Predictor of Longer Overall Survival in Epithelial Ovarian Cancer
}

\author{
MAROUA MANAI ${ }^{1,2,3}$, RAOUDHA DOGHRI ${ }^{1 *}$, PASCAL FINETTI ${ }^{3 *}$, KARIMA MRAD $^{1,2^{*}}$, RIHAB BOUABSA $^{1}$, \\ MOHAMED MANAI ${ }^{2}$, DANIEL BIRNBAUM ${ }^{3}$, FRANÇOIS BERTUCCI $^{3,4,5}$, LAMIA CHARFI $^{1,2}$ and MAHA DRISS ${ }^{1,2}$ \\ ${ }^{1}$ Anatomic Pathology Department, Salah Azaiez Institute, Tunis, Tunisia; \\ ${ }^{2}$ Laboratory of Mycology, Pathologies and Biomarkers (LR16ESO5), Biology Department, \\ Faculty of Sciences of Tunis, University of Tunis El Manar, Tunis, Tunisia; \\ ${ }^{3}$ Department of Predictive Oncology, Cancer Research Center of Marseille, \\ Aix Marseille University, Marseille, France; \\ ${ }^{4}$ Training and Research Unit of Medicine, Aix Marseille University, Marseille, France; \\ ${ }^{5}$ Department of Medical Oncology, Paoli-Calmettes Institute, Marseille, France
}

\begin{abstract}
Background: Epithelial ovarian cancer (EOC) is the major gynecological cause of cancer deaths. Annexin Al (ANXA1) protein has been implicated in the aggressiveness of several cancer types. Materials and Methods: This study retrospectively assessed ANXA1 expression in epithelial cells of 156 pre-chemotherapy EOC samples and 34 normal ovarian samples from patients treated at Salah Azaiez Institute. Using immunohistochemistry, ANXAl expression was compared in normal versus cancer samples; correlations with clinicopathological features, including overall survival, were sought. Results: Fifty-two percent of tumor samples showed epithelial ANXAl staining versus only $26 \%$ of normal samples (Fisher's exact test, $p=0.00794$ ). Epithelial ANXA1 expression was correlated with better overall survival in both univariate and multivariate analyses. Conclusion: The possible contribution of ANXA1 overexpression to EOC outcome may be relevant to therapeutic strategies.
\end{abstract}

Epithelial ovarian cancer (EOC) is the most lethal gynecological neoplasia because of its late diagnosis and high recurrence rate; it has the poorest outcome (1). Most women are diagnosed with late-stage disease $(1,2)$. Early

This article is freely accessible online.

*These Authors contributed equally and should be considered as second co-authors.

Correspondence to: Dr. Maroua Manai, Anatomic Pathology Department, Salah Azaiez Institute, Boulevard 9 Avril, Zip Code 1006, Tunis, Tunisia. E-mail: maroua.m@hotmail.com

Key Words: Epithelial ovarian cancer, ANXA1, immunohistochemistry, prognosis, survival. methods of detection are lacking and new therapeutic approaches to reduce mortality are unsuccessful because of the lack of comprehension of the origin and pathogenesis of EOC. At the epidemiological level, EOC is the second gynecological cancer in Tunisia with an incidence rate of just under 4 per 100,000 inhabitants (3). EOC has four major pathological types: $75 \%$ are serous, $10 \%$ are endometrioid, $3 \%$ mucinous, and $10 \%$ clear-cell. These types differ in pathogenesis, molecular alterations, and prognosis $(4,5)$. Features such as patient's age, International Federation of Gynecology and Obstetrics (FIGO) stage, pathological tumor grade and type, and quality of initial surgery are the current prognostic features used in decisions on chemotherapy. Despite the multimodality treatment based on surgery and paclitaxel/platinum-based chemotherapy (6-8), the 5-year overall survival rate remains poor at $30 \%$. In Tunisian patients, 5-year survival is approximately $25 \%$ (9-11).

The common alteration associated with patient survival in ovarian carcinomas appears to be in the activation of the phosphatidylinositide 3-kinase (PI3K)/protein kinase B or AKT(AKT)/mammalian target of rapamycin (mTOR) signaling cascade (12). The main objective of our research team is to study the different biomarkers implicated in this signaling pathway in epithelial cells of EOC samples prior to chemotherapy. Our previous study was about overexpression of stromal myristoylated alanine-rich C-kinase substrate (MARCKS) and its association with poor prognosis in EOC (13). MARCKS is associated with actin cytoskeletal remodelling, cell proliferation and motility, and promotes PI3K/AKT signaling pathways (14). It was found in the literature that alteration of annexin A1 (ANXA1) protein expression may activate the PI3K/AKT/mTOR signaling pathway and contribute to aggressive tumor behavior (12). 
ANXA1 is a ubiquitous $37-\mathrm{kDa}$ protein that belongs to the family of calcium/phospholipid-binding proteins $(14,15)$. It is expressed in various tissues and involved in several biological processes such as calcium signaling, membrane aggregation, inflammation, phagocytosis, cell proliferation, apoptosis and tumor progression $(12,16-20)$.

Accumulated evidence indicates that ANXA1 deregulation is associated with tumor development, progression, invasion, metastasis, and drug resistance in many cancer types $(16,17$, $21,22)$. Paclitaxel resistance is the main cause of ovarian cancer failure (19). Low ANXA1 protein expression was found to be associated with paclitaxel resistance in ovarian cancer (21). Moreover, ANXA1 overexpression has been found to correlate with tumor proliferation in breast, endometrial, colorectal, lung and pancreatic cancer, and melanoma (20,23-25). In contrast, loss of ANXA1 expression has been observed in cancer of the prostate, esophagus, cervix and lymphoma $(17,26)$. ANXA1 maybe a tumor promoter depending on the type of tissue and cancer (17). Alteration of its expression might be explained by certain mechanisms including amplification or hypermethylation of its gene, allelic losses and post-translational modifications $(26,27)$.

Here, we retrospectively analyzed ANXA1 protein expression in tumor samples from patients with EOC treated at our Institution (Salah Azaiez Institute of Tunis, Tunisia), and sought correlations with clinicopathological features and overall survival (OS).

\section{Patients and Methods}

Patients. In this retrospective study, pre-therapeutic diagnostic tumor samples were collected from 156 patients with EOC treated at the Institute Salah Azaiez of Tunis between 2009 and 2016. Main inclusion criteria were pathologically confirmed EOC, available formaldehyde-fixed and paraffin-embedded pre-therapeutic diagnostic tumor sample, clinicopathological annotations and written informed consent. This study was approved by the Review Board of Salah Azaiez Institute of Tunis.

Tissue microarray (TMA) construction. One TMA was available for all 156 cases and 34 normal ovarian tissues. The TMA was constructed as previously described, with slight modifications (28, 29). Two pathologists reviewed the histological samples and two representative tumor areas were carefully selected from a hematoxylin-eosin-stained section of the donor block. Tissue cores with a diameter of $0.6 \mathrm{~mm}$ from each case were selected from each of these areas and embedded in the recipient paraffin block using a specific arraying device (Alphelys, Plaisir, France). Finally, 4- $\mu \mathrm{m}$ sections were cut and used for further research using immunohistochemistry (IHC).

Immunohistochemical analysis. Protein expression of ANXA1 was analyzed by immunohistochemistry using mouse monoclonal mAb\#610066, clone 29 from BD Bioscience (Ozyme, Paris, France) diluted at 1/2000. ANXA1 expression was assessed on TMA for the $156 \mathrm{EOC}$ and 34 normal ovarian tissues using standard IHC
Table I. Clinicopathological characteristics of patients.

\begin{tabular}{llc}
\hline Characteristic & & Value \\
\hline Age, years & Median (range) & $56(27-90)$ \\
Pathological type, n (\%) & Clear-cell & $8(5 \%)$ \\
& Endometrioid & $4(2 \%)$ \\
& Mixed & $6(4 \%)$ \\
& Mucinous & $1(1 \%)$ \\
& Serous & $147(88 \%)$ \\
FIGO stage, n (\%) & Undifferentiated & $1(1 \%)$ \\
& $1-2$ & $20(12 \%)$ \\
Pathological grade, n (\%) & $3-4$ & $146(88 \%)$ \\
& 1 & $9(5 \%)$ \\
Adjuvant/neo-adjuvant & $2-3$ & $157(95 \%)$ \\
chemotherapy, n (\%) & No & $16(11 \%)$ \\
Surgery, n (\%) & Yes & $132(89 \%)$ \\
& No & $2(1 \%)$ \\
Macroscopic residual disease & Yes & $163(99 \%)$ \\
after surgery, n (\%) & Yes & $69(59 \%)$ \\
Death, n (\%)* & No & $48(41 \%)$ \\
& Yes & $60(52 \%)$ \\
& & $55(48 \%)$ \\
\hline 5-Year OS* & Rate (95\% CI) & $34 \%(24-49 \%)$ \\
OS, months* & Median (range) & $35(1-140)$ \\
\hline
\end{tabular}

FIGO: International Federation of Gynecology and Obstetrics; OS: overall survival. *For 115 patients treated with surgery and carboplatinpaclitaxel chemotherapy and with available follow-up.

protocols as previously described (13). Sections counterstained with hematoxylin were independently evaluated by two experienced ovarian pathologists (RD and MD) using light microscopy. Immunoreactivities were scored mainly by measuring the percentage of positive tumor cells, from $0 \%$ to $100 \%$. ANXA1 expression percentage was discretized using 10-fold cross-validation with the Cox proportional hazards model. Briefly, samples were first split into 10 groups and the likelihood of OS was predicted for samples for each group using Cox regression model built with the other sample groups. The survival probability of all excluded samples was found to be significant (Wald test, $p=0.0182$ ) and within each of the iteration cut-offs were found homogenous, i.e. $55 \%$ [ $t$-test, $95 \%$ confidence intervaI $(\mathrm{CI})=(53-57 \%), p<0.0001]$. Thus, ANXA1negative cases were defined by having $55 \%$ or less tumor cells stained and positive cases by more than $55 \%$ of tumor cells stained.

Statistical analysis. Data are summarized by numbers and percentages for categorical variables, median and range for continuous variables. Mann-Whitney test and Fisher's exact test were used when appropriate to analyze correlations between tumor groups and clinicopathological features. OS was calculated from the date of diagnosis to the date of death. Follow-up was calculated from the date of diagnosis to the date of last news for event-free patients. OS curves were defined using the Kaplan-Meier method and were compared with the log-rank test. Uni- and multivariate prognostic analyses for OS were also performed using Cox regression analysis (Wald test). All statistical tests were considered significant for $p$-value of 0.05 or less. Analyses were conducted by using the survival package (version 

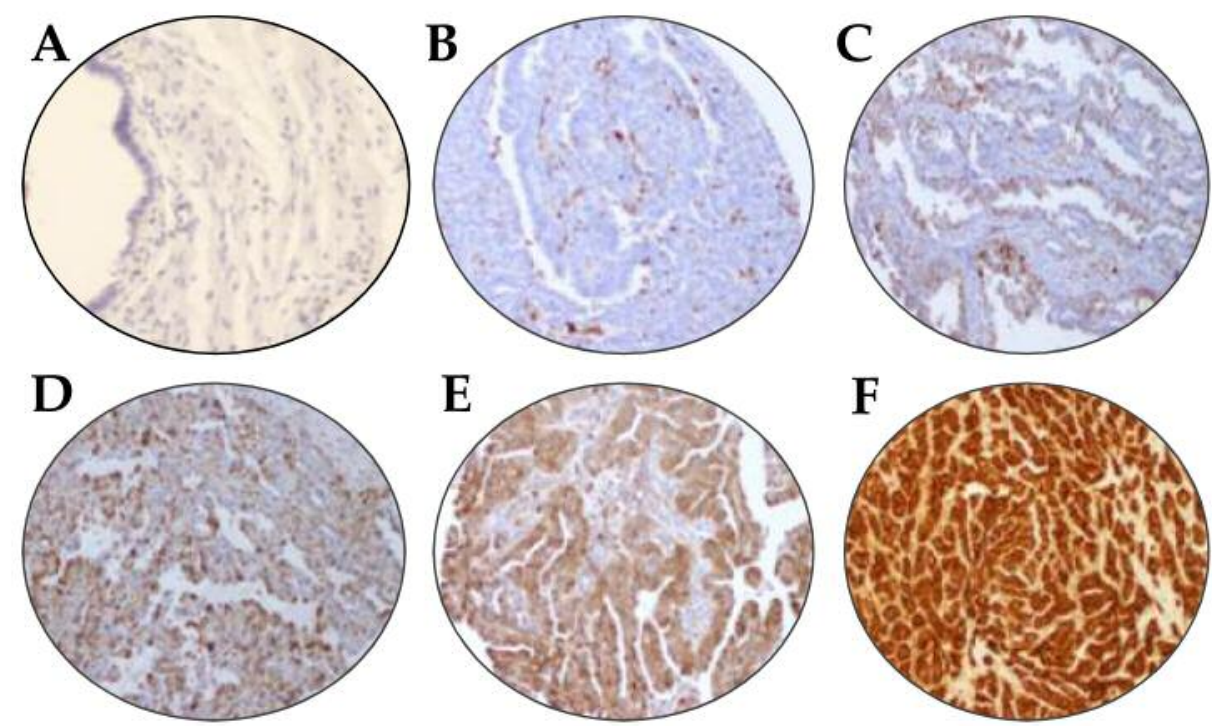

Figure 1. Representative images of epithelial annexin A1 immuno-histochemistry staining in normal ovary (A: 0\% positive cells), and in primary epithelial ovarian cancer samples with different percentages of stained cancer cells (B-F). B: Negative staining, 0\%; C: 30\% staining, weakly positive; D and E: Moderately positive staining, $60 \%$ and $80 \%$, respectively; F: $100 \%$, strongly positive staining $(\times 200)$.

2.30) in the R software (version 2.15.2; http://www.cran.r-project.org/). The reporting recommendations for tumor marker prognostic studies (REMARK criteria) were followed (30).

\section{Results}

Patient population and clinicopathological features. The clinicopathological features of all samples $(\mathrm{N}=156)$ are shown in Table I. Patients with EOC had a median age of 56 years at diagnosis (range=27-90). As expected, FIGO advanced stage 3-4 was seen in $88 \%$ of patients, including 44 with stage 4 (27\%). The most frequent pathological type was serous $(88 \%)$, followed by clear cell carcinoma $(5 \%)$, mixed $(4 \%)$, and endometrioid (2\%). Most patients had tumor of a high-grade (grade 2-3; 95\%). All patients underwent surgery before or after chemotherapy, with a residual macroscopic tumor at the end of surgical procedure present in $41 \%$ of cases. Most of the patients received adjuvant/ neoadjuvant chemotherapy (89\%). The 5-year OS rate was 34\% (95\% CI=24-49\%) in the 115 patients treated with surgery and carboplatin-paclitaxel chemotherapy and with available follow-up.

ANXA1 is significantly overexpressed in EOC. ANXA1 expression was measured using IHC in the 156 tumor samples and 34 normal samples in the TMA. Figure 1 shows examples of staining and results are summarized in Figure 2. In both tumor and normal samples, staining was observed mainly in epithelial cells. It was mainly located in the cytoplasm, but some samples showed nuclear staining. No correlation was established between nuclear staining and clinical features. Staining was observed mainly in tumor epithelial cells, and

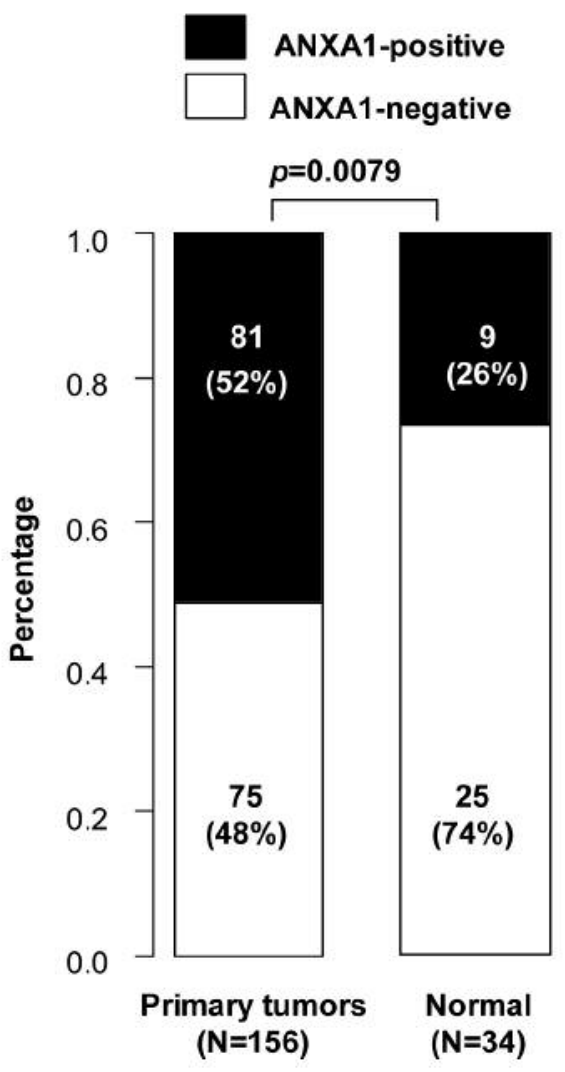

Figure 2. Annexin Al (ANXA1) expression in ovarian carcinomas and normal ovarian samples. Box plots showing the percentage of ANXA1positive samples and ANXA1-negative samples for the epithelial staining in tissue from normal and primary tumors. The p-values are for Fisher's exact test. 
Table II. Clinicopathological correlations with annexin A1 (ANXA1) expression.

\begin{tabular}{|c|c|c|c|c|c|}
\hline \multirow[b]{2}{*}{ Characteristic } & & \multirow[b]{2}{*}{$\mathrm{N}$} & \multicolumn{3}{|c|}{ ANXA1 status } \\
\hline & & & Negative $(\mathrm{N}=75)$ & Positive $(\mathrm{N}=81)$ & $p$-Value \\
\hline Age, years & Median (range) & 156 & $57(33-90)$ & $55(27-80)$ & 0.090 \\
\hline \multirow[t]{6}{*}{ Histological type, n (\%) } & Clear-cell & 8 & $3(4 \%)$ & $5(6 \%)$ & 0.711 \\
\hline & Endometrioid & 4 & $3(4 \%)$ & $1(1 \%)$ & \\
\hline & Mixed & 6 & $3(4 \%)$ & $3(4 \%)$ & \\
\hline & Mucinous & 1 & $1(1 \%)$ & $0(0 \%)$ & \\
\hline & Serous & 135 & $64(86 \%)$ & $71(88 \%)$ & \\
\hline & Undifferentiated & 1 & $0(0 \%)$ & $1(1 \%)$ & \\
\hline \multirow[t]{2}{*}{ FIGO stage, n (\%) } & $1-2$ & 18 & $9(12 \%)$ & $9(11 \%)$ & $>0.99$ \\
\hline & $3-4$ & 136 & $66(88 \%)$ & $70(89 \%)$ & \\
\hline \multirow[t]{2}{*}{ Pathological grade, n (\%) } & 1 & 7 & $2(3 \%)$ & $5(6 \%)$ & 0.447 \\
\hline & $2-3$ & 147 & $71(97 \%)$ & $76(94 \%)$ & \\
\hline \multirow[t]{2}{*}{ Adjuvant/neo-adjuvant chemotherapy, n (\%) } & No & 15 & $9(15 \%)$ & $6(8 \%)$ & 0.274 \\
\hline & Yes & 121 & $52(85 \%)$ & $69(92 \%)$ & \\
\hline \multirow[t]{2}{*}{ Surgery, n (\%) } & No & 1 & $1(1 \%)$ & $0(0 \%)$ & 0.481 \\
\hline & Yes & 153 & $73(99 \%)$ & $80(100 \%)$ & \\
\hline \multirow[t]{2}{*}{ Macroscopic residual disease after surgery, $\mathrm{n}(\%)$} & No & 62 & $30(64 \%)$ & $32(53 \%)$ & 0.326 \\
\hline & Yes & 45 & $17(36 \%)$ & $28(47 \%)$ & \\
\hline \multirow[t]{2}{*}{ Death, $\mathrm{n}(\%)^{*}$} & No & 60 & $19(39 \%)$ & $41(62 \%)$ & 0.0151 \\
\hline & Yes & 55 & $30(61 \%)$ & $25(38 \%)$ & \\
\hline 5-Year OS* & Rate $(95 \% \mathrm{CI})$ & 115 & $22 \%(10-47)$ & $46 \%(31-67)$ & 0.0265 \\
\hline
\end{tabular}

FIGO: International Federation of Gynecology and Obstetrics; OS: overall survival; CI: confidence interval. *For 115 patients treated with surgery and carboplatin-paclitaxel chemotherapy and with available follow-up.

was only weakly expressed in normal cells. Using $55 \%$ stained epithelial cells as a cut-off for positivity, $26 \%$ of normal samples were ANXA1-positive versus $52 \%$ of tumor samples (Fisher's exact test, $p=0.00794$ ).

Association of ANXA1 expression and clinicopathological features. We sought correlations between binary ANXA1 IHC status (81 positive and 75 negative) and the following clinicopathological features: patient age, FIGO stage, pathological type and grade, macroscopic tumor residue after debulking surgery and primary response to chemotherapy (Table II). We did not find any correlation between ANXA1 IHC status and any of the tested variables. However, ANXA1 positivity was associated with fewer deaths (38\%) than ANXA1 negativity (61\%) (Fisher's exact test, $p=0.0151)$.

In univariate analysis for OS (Table III), ANXA1 positivity was associated with longer OS with a hazard ratio (HR) for death of 0.54 (95\% CI=0.31-0.94) when compared with ANXA1 negativity (Wald test, $p=0.0288$ ). Stage 3-4 FIGO was also associated with shorter OS (Wald test, $p=0.0487$ ). In multivariate analysis (Table III), those two variables remained significant, suggesting an independent prognostic value for ANXA1 status. The HR for death was 0.52 (95\% CI=0.30$0.90)$ in the ANXA1-positive group when compared with the ANXA1-negative group (Wald test, $p=0.0265$ ).
ANXA1 overexpression is associated with longer OS. We thus assessed the prognostic value of ANXA1 expression in terms of OS in the population of 115 patients treated with surgery and carboplatin-paclitaxel chemotherapy and with available follow-up. Forty-nine cases were ANXA1negative and 66 were ANXA1-positive. The 5-year OS was significantly longer in the ANXA1-positive group $(46 \%, 95 \% \mathrm{CI}=31-67 \%)$ than in the ANXA1-negative group $(22 \%, 95 \% \mathrm{CI}=10-47 \%)$ (log-rank test, $p=0.0265$, Figure 3).

\section{Discussion}

Despite advances in treatment of ovarian carcinoma over the past few decades, the survival of patients with ovarian cancer is still unfavorable and the identification of new therapeutic markers and targets is required to improve treatment and increase survival. Our objective was to analyze the IHC expression of ANXA1 in a large retrospective series of ovarian carcinomas $(\mathrm{N}=156)$ and normal ovary samples $(\mathrm{N}=34)$ and to search for correlations with clinicopathological features. Our results show ANXA1 expression to be more frequent in ovarian cancer samples than in normal ovarian samples and to be associated with longer OS at 5 years in both uni-and multivariate analyses. 


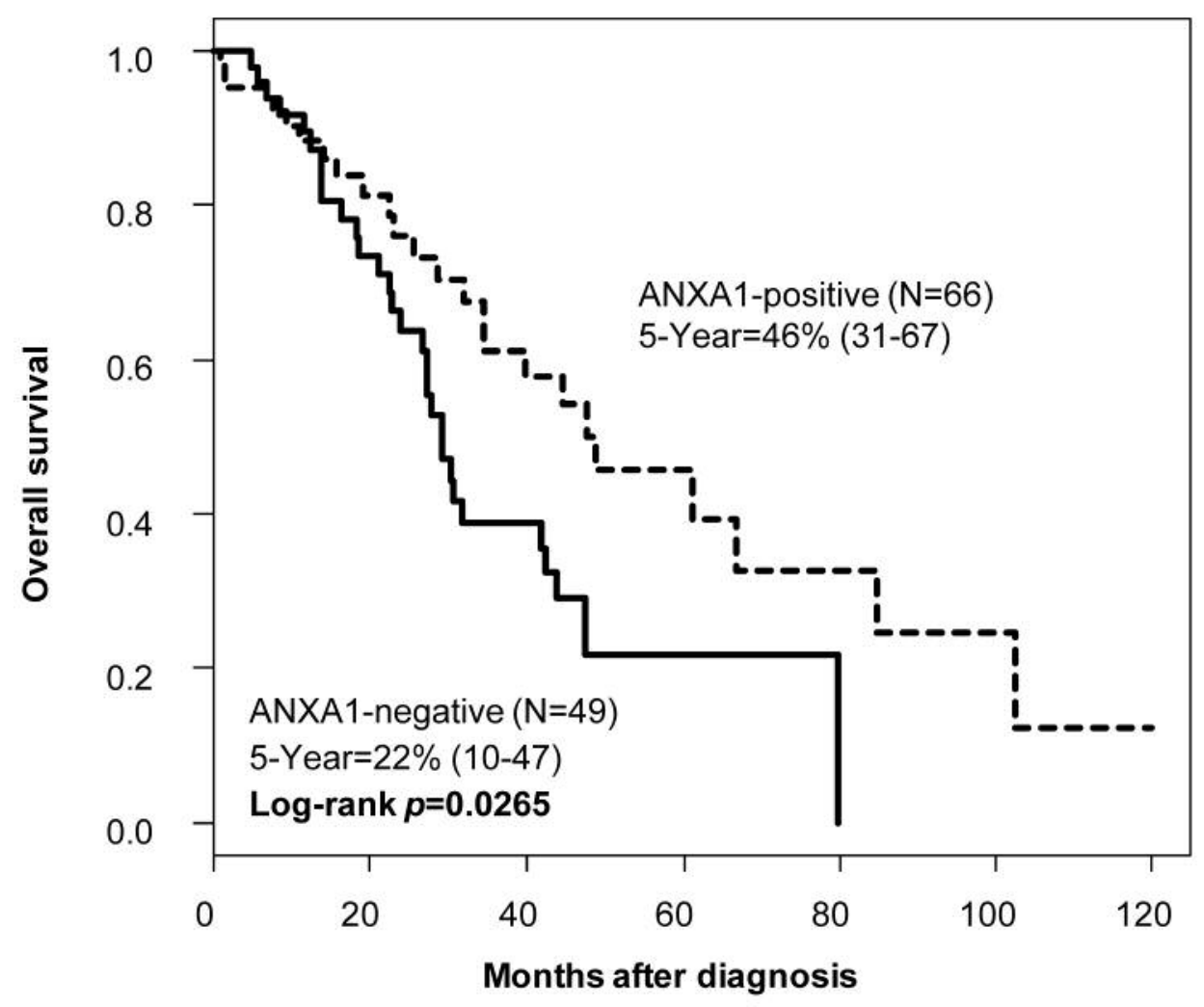

Figure 3. Kaplan-Meier curve of overall survival for 115 patients treated with surgery and carboplatin-paclitaxel chemotherapy for epithelial ovarian cancer and with available follow-up according to epithelial annexin Al (ANXA1) status.

Table III. Univariate and multivariate analysis for overall survival.

\begin{tabular}{|c|c|c|c|c|c|c|c|}
\hline \multirow[t]{2}{*}{ Characteristics } & & \multicolumn{3}{|c|}{ Univariate } & \multicolumn{3}{|c|}{ Multivariate } \\
\hline & & $\mathrm{N}$ & HR $(95 \% \mathrm{CI})$ & $p$-Value & $\mathrm{N}$ & HR $(95 \% \mathrm{CI})$ & $p$-Value \\
\hline Age & & 115 & $1.02(1.0-1.0)$ & 0.124 & & & \\
\hline \multirow[t]{3}{*}{ Pathological type } & Endometrioid $v s$. clear-cell & 115 & $2.10(0.3-13)$ & 0.332 & & & \\
\hline & Mixed vs. clear-cell & & $1.37(0.3-6.9)$ & & & & \\
\hline & Serous $v s$. clear-cell & & $0.70(0.2-2.3)$ & & & & \\
\hline FIGO stage & 3-4 vs. $1-2$ & 113 & $5.68(1.3-24)$ & 0.0187 & 113 & $5.35(1.2-23)$ & 0.0246 \\
\hline Pathological grade & 2-3 vs. 1 & 115 & $1.04(0.5-2.2)$ & 0.919 & & & \\
\hline $\begin{array}{l}\text { Macroscopic residual disease } \\
\text { after surgery }\end{array}$ & Yes $v s$. no & 97 & $0.77(0.4-1.4)$ & 0.374 & & & \\
\hline ANXA1 IHC & Positive $v s$. negative & 115 & $0.54(0.3-0.9)$ & 0.0288 & 113 & $0.52(0.3-0.9)$ & 0.0265 \\
\hline
\end{tabular}

HR: Hazard ratio; CI: confidence interval; FIGO: International Federation of Gynecology and Obstetrics; ANXA1: annexin A1.

We focused on ANXA1 protein expression for several reasons: i) ANXA1 has a proven role in cancer progression, including therapeutic resistance (21); ii) ANXA1 has been characterized as a potential molecular marker for diagnosis, treatment and/or prognosis in different cancer types; iii) a monoclonal antibody is commercially available performing sufficiently well in IHC on paraffin-embedded tissues. ANXA1 belongs to the annexin superfamily of $\mathrm{Ca}^{2+}$-dependent phospholipid-binding proteins (15). Recent evidence indicates that alteration of ANXA1 protein expression may activate the $\mathrm{PI} 3 \mathrm{~K} / \mathrm{AKT} / \mathrm{mTOR}$ signaling pathway and contribute to tumor progression and aggressive tumor behavior $(12,22)$. 
We found heterogeneous ANXA1 staining in EOC. Fifty-two percent of tumor samples showed ANXA1 immunostaining versus only $26 \%$ of normal samples. In the literature and to our knowledge, only one study analyzed the expression of ANXA1 by IHC in a series of 42 ovarian carcinomas including paclitaxelresistant and paclitaxel-sensitive tumors (31). The authors showed that the expression of ANXA1 was lower in paclitaxelresistant samples than in -sensitive samples. Weaker expression of ANXA1 was found in tumors with advanced clinical stage, suggesting that the loss of ANXA1 expression contributes to increasing the proliferative, invasive and metastatic potential of ovarian cancer cells. A decrease in ANXA1 expression was also observed in cisplatin-resistant ovarian cancer cell lines compared to a platinum-sensitive parental line (32).

In our series, uni- and multivariate analyses showed that epithelial ANXA1 expression was associated with good OS. These results suggest that overexpression of ANXA1 may be a biomarker of good prognosis and are in favor of its role of as a tumor suppressor. Another IHC study on a series of 135 breast cancer cases showed that low expression of ANXA1 was associated with advanced disease and shorter OS compared to high expression (33). Furthermore, the reexpression of ANXA1 in metastatic breast cancer cell lines restored chemosensitivity and suppresses metastases $(34,35)$.

In contrast, other studies demonstrated an oncogenic role for ANXA1 in ovarian cancer. Studies conducted in vitro highlighted its role in the chemoresistance of ovarian carcinoma. Comparative proteomic analysis on paclitaxelresistant and -sensitive parental cell lines (SKpac and SKOV3, respectively) showed that ANXA1 was overexpressed in resistant cell lines. In the same study, ANXA1 was overexpressed (2-3 fold) in serous carcinoma compared to benign serous tumors and phospho-ANXA1 was highly expressed in tumor samples versus normal tissues (36). The relationship between ANXA1 and tumorigenesis might be due to its being a major substrate of epidermal growth factor and other kinases involved in tumor development such as mitogenactivated protein kinases, PI3K and AKT (17).

Several studies in other types of cancer have suggested the crucial role of ANXA1 in cancer progression including chemoresistance, and its interest as a novel therapeutic target.

In vitro and in vivo approaches in pancreatic cancer showed that ANXA1 inhibition led to a significant decrease in migration, cell invasion and metastatic power (37). ANXA1 might be a key mediator of the processes associated with hypoxia-related metastasis in prostate cancer (38). In cutaneous melanoma and lung cancer, using in vivo models, tumors in ANXAl-knockout mice showed attenuated tumor progression, and reduced growth and vascularization compared with wild-type control models (39). The oncogenic role of ANXA1 in lung cancer was demonstrated on a panel of 125 tumor tissues including primary tumors and paired lymph node metastases. Proteomic analysis identified ANXA1 as the second most highly regulated protein in lung cancer with lymph node metastases. In addition, the overexpression of ANXA1 was validated by IHC and was found to be associated with shorter relapse-free survival and OS. Finally, in vitro study of the A549 lung cancer cell line showed that inhibition of ANXA1 expression by siRNA led to a significant decrease in invasiveness (23). These results indicate a crucial role for ANXA1 in potentiating lung cancer cell migration, metastasis and growth, and suggest a potential use of ANXA1 inhibitors in the treatment of lung cancer progression.

Thus, finding overexpression of ANXA1 in EOC versus normal ovarian tissue, and its association with good independent prognostic value in ovarian cancer, are consistent with the clinical and pre-clinical findings published on ovarian cancer and breast cancer.

While there are several biomarkers for ovarian carcinoma, there remains a need to find suitable protein biomarkers and potential targets for future therapies. Future directions in this work include evaluating a larger and prospective cohort of patients in order to determine whether the expression of these biomarkers might have clinical application.

In conclusion, our results confirm the literature data regarding the controversial role of ANXA1 in different types of cancer. We showed overexpression of ANXA1 in EOC versus normal ovarian samples, and its association with longer OS in univariate and multivariate analyses. The strength of our study includes the testing specifically for the protein expression of ANXA1 with a total of 156 samples of ovarian carcinoma. Limitations include its retrospective nature and associated biases. Our results suggest that ANXA1 might be an early diagnostic factor and a potential therapeutic target in ovarian carcinomas. However, other studies are needed to better understand the involvement of ANXA1 during tumor evolution and chemoresistance, its implication in the metastatic potential of EOC, and, of course, to determine if the expression of this biomarker has any clinical application.

\section{Conflicts of Interest}

The Authors declare no conflicts of interest in regard to this study.

\section{Authors' Contributions}

MaM and FB conceived and designed the experiments. MaM, RD, $\mathrm{MD}, \mathrm{RB}$, providing the data and performed the experiments. MaM, $\mathrm{PF}$, and FB analyzed data. MM, RD, and FB wrote the article. LC, $\mathrm{MM}, \mathrm{DB}$, and KM critically revised the article and gave final approval of the version to be published.

\section{Acknowledgements}

The Authors would like to thank the Salah Azaiez Institute of Tunis, Tunisia, Inserm; Paoli-Calmettes Institute, Marseille, France; the Faculty of Science of Tunis; the University of Tunis El Manar; and the Ministry of Higher Education for Scientific Research of Tunisia, Tunis, Tunisia. 
This work was supported by SIRIC (grant no. INCa-DGOSInserm 6038) and Paoli-Calmettes Institute; National League Against Cancer (received by DB; grant no. R16009AA). MaM was in part funded by a Joint Committee of University Cooperation PHCUtique in a Franco-Tunisian mixed research project (received by MaM; grant no. 15G0805).

\section{References}

1 SEER Cancer Statistics Factsheets: Ovary Cancer. National Cancer Institute. Available at: https://seer.cancer.gov/statfacts/ html/ovary.html

2 American Cancer Society. Cancer Facts \& Figures 2015. Atlanta, 2015. Available at: https://www.cancer.org/ research/cancer-facts-statistics/all-cancer-facts-figures/cancerfacts-figures-2015.html

3 Ferlay J, Soerjomataram I, Dikshit R, Eser S, Mathers C, Rebelo M, Parkin DM, Forman D and Bray F: Cancer incidence and mortality worldwide: sources, methods and major patterns in GLOBOCAN 2012. Int J Cancer 136: E359-386, 2015. PMID: 25220842. DOI: $10.1002 / \mathrm{ijc} .29210$

4 Vang R, Shih I-M and Kurman RJ: Ovarian low-grade and highgrade serous carcinoma: pathogenesis, clinicopathologic and molecular biologic features, and diagnostic problems. Adv Anat Pathol 16: 267-282, 2009. PMID: 19700937. DOI: 10.1097/ PAP.0b013e3181b4fffa

5 Shih I-M and Kurman RJ: Ovarian tumorigenesis: a proposed model based on morphological and molecular genetic analysis. Am J Pathol 164: 1511-1518, 2004. PMID: 15111296. DOI: 10.1016/s0002-9440(10)63708-x

6 Ledermann JA, Raja FA, Fotopoulou C, Gonzalez-Martin A, Colombo N, Sessa C and ESMO Guidelines Working Group: Newly diagnosed and relapsed epithelial ovarian carcinoma: ESMO Clinical Practice Guidelines for diagnosis, treatment and follow-up. Ann Oncol 24 Suppl 6: vi24-32, 2013. PMID: 24078660. DOI: $10.1093 /$ annonc/mdt333

7 Tothill RW, Tinker AV, George J, Brown R, Fox SB, Lade S, Johnson DS, Trivett MK, Etemadmoghadam D, Locandro B, Traficante N, Fereday S, Hung JA, Chiew YE, Haviv I, Australian Ovarian Cancer Study Group, Gertig D, DeFazio A, Bowtell DD: Novel molecular subtypes of serous and endometrioid ovarian cancer linked to clinical outcome. Clin Cancer Res 14: 5198-5208, 2008. PMID: 18698038. DOI: 10.1158/1078-0432.CCR-08-0196

8 Morgan RJ Jr, Armstrong DK, Alvarez RD, Bakkum-Gamez JN, Behbakht K, Chen LM, Copeland L, Crispens MA, DeRosa M, Dorigo O, Gershenson DM, Gray HJ, Hakam A, Havrilesky LJ, Johnston C, Lele S, Martin L, Matulonis UA, O'Malley DM, Penson RT, Percac-Lima S, Pineda M, Plaxe SC, Powell MA, Ratner E, Remmenga SW, Rose PG, Sabbatini P, Santoso JT, Werner TL, Burns J, Hughes M.: Ovarian Cancer, Version 1.2016, NCCN Clinical Practice Guidelines in Oncology. J Natl Compr Canc Netw 14(9): 1134-1163, 2016. PMID: 27587625. DOI: $10.6004 /$ jncen.2016.0122

9 Liao J, Qian F, Tchabo N, Mhawech-Fauceglia P, Beck A, Qian Z, Wang X, Huss WJ, Lele SB, Morrison CD and Odunsi K: Ovarian cancer spheroid cells with stem cell-like properties contribute to tumor generation, metastasis and chemotherapy resistance through hypoxia-resistant metabolism. PLoS ONE 9: e84941, 2014. PMID: 24409314. DOI: 10.1371/journal.pone. 0084941
10 Stark D, Nankivell M, Pujade-Lauraine E, Kristensen G, Elit L, Stockler M, Hilpert F, Cervantes A, Brown J, Lanceley A, Velikova G, Sabate E, Pfisterer J, Carey MS, Beale P, Qian W, Swart AM, Oza A and Perren T: Standard chemotherapy with or without bevacizumab in advanced ovarian cancer: quality-of-life outcomes from the International Collaboration on Ovarian Neoplasms (ICON7) phase 3 randomised trial. Lancet Oncol 14(3): 236-243, 2013. PMID: 23333117. DOI: 10.1016/S1470-2045(12)70567-3

11 Ben Fatma L, Hochlef M, Gharbi O, Landolsi A, Limam S, Chabchoub I, Cherif N, Bouguizene S, Yacoubi T, Bibi M, Khairi $\mathrm{H}$ and Ben Ahmed S: Epithelial advanced ovarian carcinoma in the central region of Tunisia: therapeutic results and prognostic factors on 104 patients. Bull Cancer 93: 12331239, 2006. PMID: 17182378. DOI: 10.1016/S1470-2045(12) 70567-3

12 Zhang L, Zheng Y-L, Hu R-H, Zhu L, Hu CC, Cheng F, Li S and Li JG: Annexin A1 mimetic peptide AC2-26inhibits sepsisinduced cardiomyocyte apoptosis through LXA4/PI3K/AKT signaling pathway. Curr Med Sci 38: 997-1004, 2018. PMID: 30536061. DOI: 10.1007/s11596-018-1975-1

13 Doghri R, Manai M, Finetti P, Driss M, Agavnian E, Lopez M, Elghardallou M, Charafe-Jauffret E, Manai M, Chaffanet M, Birnbaum D, Mrad K and Bertucci F: Stromal expression of MARCKS protein in ovarian carcinomas has unfavorable prognostic value. Int J Mol Sci 19(1): 41, 2017. PMID: 29295532. DOI: $10.3390 / \mathrm{ijms} 19010041$

14 Chen C-H, Fong LWR, Yu E, Wu R, Trott JF and Weiss RH: Upregulation of MARCKS in kidney cancer and its potential as a therapeutic target. Oncogene 36: 3588-3598, 2017. PMID: 28166200. DOI: $10.1038 /$ onc. 2016.510

15 Crumpton MJ and Dedman JR: Protein terminology tangle. Nature 345(6272): 212, 1990. PMID: 2333094. DOI: 10.1038/ $345212 \mathrm{a} 0$

16 de Graauw M, van Miltenburg MH, Schmidt MK, Pont C, Lalai R, Kartopawiro J, Pardali E, Le Dévédec SE, Smit VT, van der Wal A, Van't Veer LJ, Cleton-Jansen AM, ten Dijke P and van de Water B: Annexin A1 regulates TGF-beta signaling and promotes metastasis formation of basal-like breast cancer cells. Proc Natl Acad Sci USA 107: 6340-6345, 2010. PMID: 20308542. DOI: 10.1073/pnas.0913360107

17 Guo C, Liu S and Sun M-Z: Potential role of Anxa1 in cancer. Future Oncol 9: 1773-1793, 2013. PMID: 24156336. DOI: 10.2217/fon.13.114

18 Boudhraa Z, Bouchon B, Viallard C, D'Incan M and Degoul F: Annexin A1 localization and its relevance to cancer. Clin Sci 130: 205-220, 2016. PMID: 26769657. DOI: 10.1042/CS20 150415

19 Stordal B, Hamon M, Mc Eneaney V, Roche S, Gillet JP, O'Leary JJ, Gottesman M and Clynes M: Resistance to paclitaxel in a cisplatin-resistant ovarian cancer cell line is mediated by P-glycoprotein. PLoS ONE 7: e40717, 2012. PMID: 22792399. DOI: 10.1371 /journal.pone.0040717

20 Sheikh MH and Solito E: Annexin A1: Uncovering the Many Talents of an Old Protein. Int J Mol Sci 19(4): 1045, 2018. PMID: 29614751. DOI: 10.3390/ijms 19041045

21 Cao L, Li X, Zhang Y, Peng F, Yi H, Xu Y, Li X and Wang Q: Proteomic analysis of human ovarian cancer paclitaxel-resistant cell lines. Zhong Nan Da Xue Xue Bao Yi Xue Ban 35: 286-294, 2010. PMID: 20448348. DOI: 10.3969/j.issn.1672-7347.2010. 04.002 
22 Zhu J-F, Huang W, Yi H-M, Xiao T, Li JY, Feng J, Yi H, Lu SS, Li XH, Lu RH, He QY and Xiao ZQ: Annexin A1-suppressed autophagy promotes nasopharyngeal carcinoma cell invasion and metastasis by PI3K/AKT signaling activation. Cell Death Dis 9(12): 1154, 2018. PMID: 30459351. DOI: 10.1038/s41419-0181204-7

23 Fang Y, Guan X, Cai T, Long J, Wang H, Xie X and Zhang Y: Knockdown of ANXA1 suppresses the biological behavior of human NSCLC cells in vitro. Mol Med Rep 13: 3858-3866, 2016. PMID: 27035116. DOI: 10.3892/mmr.2016.5022

24 Zóia MAP, Azevedo FVP, Vecchi L, Mota STS, Rodovalho VR, Cordeiro AO, Correia LIV, Silva ACA, Ávila VMR, Araújo TG and Goulart LR: Inhibition of triple-negative breast cancer cell aggressiveness by cathepsin D blockage: role of annexin A1. Int J Mol Sci 20(6): 1337, 2019. PMID: 30884823. DOI: 10.3390/ ijms20061337

25 Belvedere R, Saggese P, Pessolano E, Memoli D, Bizzarro V, Rizzo F, Parente L, Weisz A and Petrella A: miR-196a Is able to restore the aggressive phenotype of annexin A1 knock-out in pancreatic cancer cells by CRISPR/Cas9 Genome Editing. Int J Mol Sci 19(7): 1967, 2018. PMID: 29986379. DOI: 10.3390/ ijms19071967

26 Lim LHK and Pervaiz S: Annexin 1: the new face of an old molecule. FASEB J 21: 968-975, 2007. PMID: 17215481. DOI.org/10.1096/fj.06-7464rev

27 Paweletz CP, Ornstein DK, Roth MJ, Bichsel VE, Gillespie JW, Calvert VS, Vocke CD, Hewitt SM, Duray PH, Herring J, Wang QH, Hu N, Linehan WM, Taylor PR, Liotta LA, Emmert-Buck MR and Petricoin EF: Loss of annexin 1 correlates with early onset of tumorigenesis in esophageal and prostate carcinoma. Cancer Res 60: 6293-6297, 2000. PMID: 11103786.

28 Ginestier C, Charafe-Jauffret E, Bertucci F, Eisinger F, Geneix J, Bechlian D, Conte N, Adélaïde J, Toiron Y, Nguyen C, Viens P, Mozziconacci MJ, Houlgatte R, Birnbaum D and Jacquemier $\mathrm{J}$ : Distinct and complementary information provided by use of tissue and DNA microarrays in the study of breast tumor markers. Am J Pathol 161: 1223-1233, 2002. PMID: 12368196. DOI: $10.1016 / \mathrm{S} 0002-9440(10) 64399-4$

29 Van den Eynden GG, Van der Auwera I, Van Laere S, Colpaert CG, van Dam P, Merajver S, Kleer CG, Harris AL, Van Marck EA, Dirix LY and Vermeulen PB: Validation of a tissue microarray to study differential protein expression in inflammatory and noninflammatory breast cancer. Breast Cancer Res Treat 85: 13-22, 2004. PMID: 15039594. DOI.org/10.1023/B:BREA.0000021028. 33926.a8

30 McShane LM, Altman DG, Sauerbrei W, Taube SE, Gion M, Clark GM and Statistics Subcommittee of the NCI-EORTC Working Group on Cancer Diagnostics: REporting recommendations for tumour MARKer prognostic studies (REMARK). Br J Cancer 93: 387-391, 2005. PMID: 16106245. DOI: 10.1038/sj.bjc.6602678
31 Zou L, Cao L and Yi H: Expression of Annexin A1 in paclitaxelresistant ovarian carcinoma and its clinical significance. Zhong Nan Da Xue Xue Bao Yi Xue Ban 39: 784-789, 2014. PMID: 25202946. DOI: 10.3969/j.issn.1672-7347.2014.08.005

32 Jin L, Huo Y, Zheng Z, Jiang X, Deng H, Chen Y, Lian Q, Ge R and Deng H: Down-regulation of Ras-related protein Rab 5Cdependent endocytosis and glycolysis in cisplatin-resistant ovarian cancer cell lines. Mol Cell Proteomics 13: 3138-3151, 2014. PMID: 25096996. DOI: 10.1074/mcp.M113.033217

33 Wang LP, Bi J, Yao C, Xu XD, Li XX, Wang SM, Li ZL, Zhang DY, Wang $M$ and Chang GQ: Annexin A1 expression and its prognostic significance in human breast cancer. Neoplasma 57: 253-259, 2010. PMID: 20353277. DOI:10.4149/neo_2010_03_253

34 Maschler S, Gebeshuber CA, Wiedemann E-M, Alacakaptan M, Schreiber M, Custic I and Beug H: Annexin A1 attenuates EMT and metastatic potential in breast cancer. EMBO Mol Med 2: 401-414, 2010. PMID: 20821804. DOI: 10.1002/emmm.2010 00095

35 Chen L, Yuan Y, Kar S, Kanchi MM, Arora S, Kim JE, Koh PF, Yousef E, Samy RP, Shanmugam MK, Tan TZ, Shin SW, Arfuso F, Shen HM, Yang H, Goh BC, Park JI, Gaboury L, Lobie PE, Sethi G, Lim LHK and Kumar AP: PPAR $\gamma$ Ligand-induced annexin A1expression determines chemotherapy response via deubiquitination of death domain kinase RIP in triple-negative breast cancers. Mol Cancer Ther 16: 2528-2542, 2017. PMID: 29021293. DOI: 10.1158/1535-7163.MCT-16-0739

36 Robinson-Bennett BL, Deford J, Diaz-Arrastia C, Levine L, Wang H-Q, Hannigan EV and Papaconstantinou J: Implications of tyrosine phosphoproteomics in cervical carcinogenesis. J Carcinog 7: 2, 2008. PMID: 18637184. DOI: 10.1186/1477-31637-2

37 Belvedere R, Bizzarro V, Forte G, Dal Piaz F, Parente L and Petrella A: Annexin A1 contributes to pancreatic cancer cell phenotype, behaviour and metastatic potential independently of formyl peptide receptor pathway. Sci Rep 6: 29660, 2016. PMID: 27412958. DOI: 10.1038/srep29660

38 Bizzarro V, Belvedere R, Migliaro V, Romano E, Parente L and Petrella A: Hypoxia regulates ANXA1 expression to support prostate cancer cell invasion and aggressiveness. Cell Adh Migr 11: 247-260, 2017. PMID: 27834582. DOI: 10.1080/19336918. 2016.1259056

39 Yi M and Schnitzer JE: Impaired tumor growth, metastasis, angiogenesis and wound healing in annexin A1-null mice. Proc Natl Acad Sci USA 106: 17886-17891, 2009. PMID: 19805119. DOI: $10.1073 /$ pnas.0901324106

Received September 2, 2019

Revised October 2, 2019

Accepted October 4, 2019 